\title{
3D end milling finite element thermal analysis
}

\author{
Andjelija. Mitrović ${ }^{1}$, Pavel. Kovač ${ }^{2,{ }^{*}}$, Nenad. Kulundžić ${ }^{2}$, Borislav. Savković, ${ }^{2}$ Ildiko. Mankova ${ }^{3}$ \\ ${ }^{1}$ Visoka škola tehničkih strukovnih studija Čačak, Svetog Save 65, 32000 Čačak, Serbia \\ ${ }^{2}$ UNS Faculty of Fechnical Sciences, Trg Dositeja Obradovića 6, 21000 Novi Sad, Serbia \\ ${ }^{3}$ Technical university in Kosice Kosice, Slovakia
}

\begin{abstract}
The paper presents a modern approach to the phenomenon of thermal analysis in end milling by the finite element method. 3D model of the end mill and work-piece was created in the software package SolidWorks. In order to predict the occurrence of thermal phenomena in milling process software package Third Wave AdvatEdge was used. Influence of cutting speed on the temperature in cutting zone was modelled and analyzed.
\end{abstract}

\section{Introduction}

Computer application has brought revolutionary changes in the field of different engineering and scientific disciplines, and one of the first was the mechanics of the solid bodies. In the number of computer calculation methods, created in the past four decades, the most widely accepted and developed is the finite element method, which, in its present form, dates from the late 1950 's.

The latest period of development is marked by the appearance of the FEM system working with discrete elements, thus enabling the simulation of gas flow with high speeds. For the reason of relative complexity of these kinds of problems, those systems are still the subject of interest for the small number of specialists.

Past years, the finite elements analysis becomes the main method in the simulation of metal cutting. Recently, programming systems are developed based on the finite elements method, which are only intended for the simulation of cutting process [1, 2]. Among scientists, that have examined this problematic couple of them have made quite interesting results $[3,4]$.

Wang and Liu [5] have estimated maximum temperatures in both tool and workpiece by a thermal method based on Green's function and a microstructurebased method in orthogonal turning. Korkut et al. [6] reported an average temperature of the chip leaving the cutting zone. Jaspers et al. [7], have also investigated the average temperature of the chip leaving the cutting zone but in this case with infrared method. Ueda et al. [8] and Tanaka et al. [9] have performed experimental investigation of the cutting tool edge temperature.

\section{Methodology and material}

Third Wave AdvantEdge is a commercial program for designing, improving and optimizing the machining process. The program structure consists of three modules: pre-process module, simulation module and post-process module. The pre-process module is the starting point that allows users to set the whole simulation, define the geometry of the tool, the properties of the materials, and the processing parameters. Simulation control data is also entered therein. The simulation module is a module where the simulation is actually performed. When the modeling data is entered and the solver simulation is started (part of the software that solves the mathematical problem) for calculations that are based on the finite element method. Since the data are completed, the post-processing module processes the results and displays them in various forms, such as graphs and images. Among the other results that can be obtained are the following: shape of the chip, temperature on the tool-chip interface, cutting forces, wear, damage and so on [10].

The AdvantEdge software package has a library with a large number of standard materials that can be used to define the material of the tool, tools and coatings. In the Tools menu, a selection of tool material and coatings is selected, and in the Workpieces menu, a selection of the material of the workpiece. The chemical composition and properties of standard materials are listed in the menu of the tool and workpiece material window. When using the coated tool, the thickness and number of coating layers (up to three layers) are defined and there is also the possibility of adding new materials to the library [11].

In the AdvantEdge software package, the simulation can be run in a demonstration or standard mode. Demonstration mode reduces time for simulation processing but provides less reliable results. Standard simulations are more reliable, more accurate and more stable than demonstration simulations.

After selecting the processing type by cutting in AdvantEdge, it is necessary to select the appropriate tool

* Corresponding author: pkovac@uns.ac.rs 
for the appropriate machining technology. In order to machining the stepped surfaces with end milling cuter (in the case of the opposite movement of the tool and the workpiece), the input parameters such as the number of rotations, step per tooth, width and depth of cutting are entered in the Process Parameters window.

For 3D simulations in AdvantEdge, under the Create / Edit Standard Workpiece / Advanced Options / Meshing Parameters option, there is a default processing that contains the corresponding network parameters. The initial network parameters define the preliminary network before the simulation starts, capture the original geometry, and define the starting points for the parameters of the custom re-networking. The Tecplot subroutine allows users to define the output parameters of the simulation to be displayed. To start the program, in order to process the simulation, select the Simulation / Submit / Submit Current Job option.

In this study, simulations of end milling were performed in AdvantEdge with high-speed steel milling tool, and the steel for the improvement of $30 \mathrm{CrNiMo} 8$ was selected for the material of the workpiece.

\section{Results of the simulation of end milling process and analyze}

3D simulations were created for the three corresponding machining regimes (Table 1) with the end milling toolmade of the high-speed steel, based on which the influence of cutting speed on the cutting temperature in the cutting zone was analyzed.

Table 1. Machining regimes during simulations.

\begin{tabular}{|l|c|c|c|}
\hline Cutting regime & $\begin{array}{c}\text { Simulation } \\
1\end{array}$ & $\begin{array}{c}\text { Simulation } \\
2\end{array}$ & $\begin{array}{c}\text { Simulation } \\
3\end{array}$ \\
\hline $\begin{array}{l}\text { cutting speed } \mathrm{v}, \\
\mathrm{m} / \mathrm{s}\end{array}$ & 0.25 & 0.29 & 0.34 \\
\hline $\begin{array}{l}\text { Feed per } \\
\text { tooth } \mathrm{s}, \mathrm{mm} / \mathrm{t}\end{array}$ & 0.045 & 0.045 & 0.045 \\
\hline $\begin{array}{l}\text { Depth of cut a, } \\
\mathrm{mm}\end{array}$ & 1.00 & 1.00 & 1.00 \\
\hline
\end{tabular}

The representations of comparative simulations was recorded at the same time intervals (by selecting the same zone being displayed) for 3 different cutting speeds are given in Figures 1, 2 and 3. A minimum temperature value of $50{ }^{\circ} \mathrm{C}$ and a maximum value of $250{ }^{\circ} \mathrm{C}$ reach(with 11 steps levels selected).

In Figure 1, the zone shortly before the outflow of the tooth from the contact with the workpiece was selected, and due to the chip that has not yet been separated, no good temperature zones near the cutting edge are seen.

In Figure 2, the display of the tool is turned off in software, in order to see better the FEM network of the workpiece in contact with the tool tooth.

Figure 3 shows the temperature of the tool from comparative simulations for three cutting speeds where it can be seen that immediately before the tooth exits from the contact, the higher tooth temperatures in the regime with a lower cutting speed are observed.

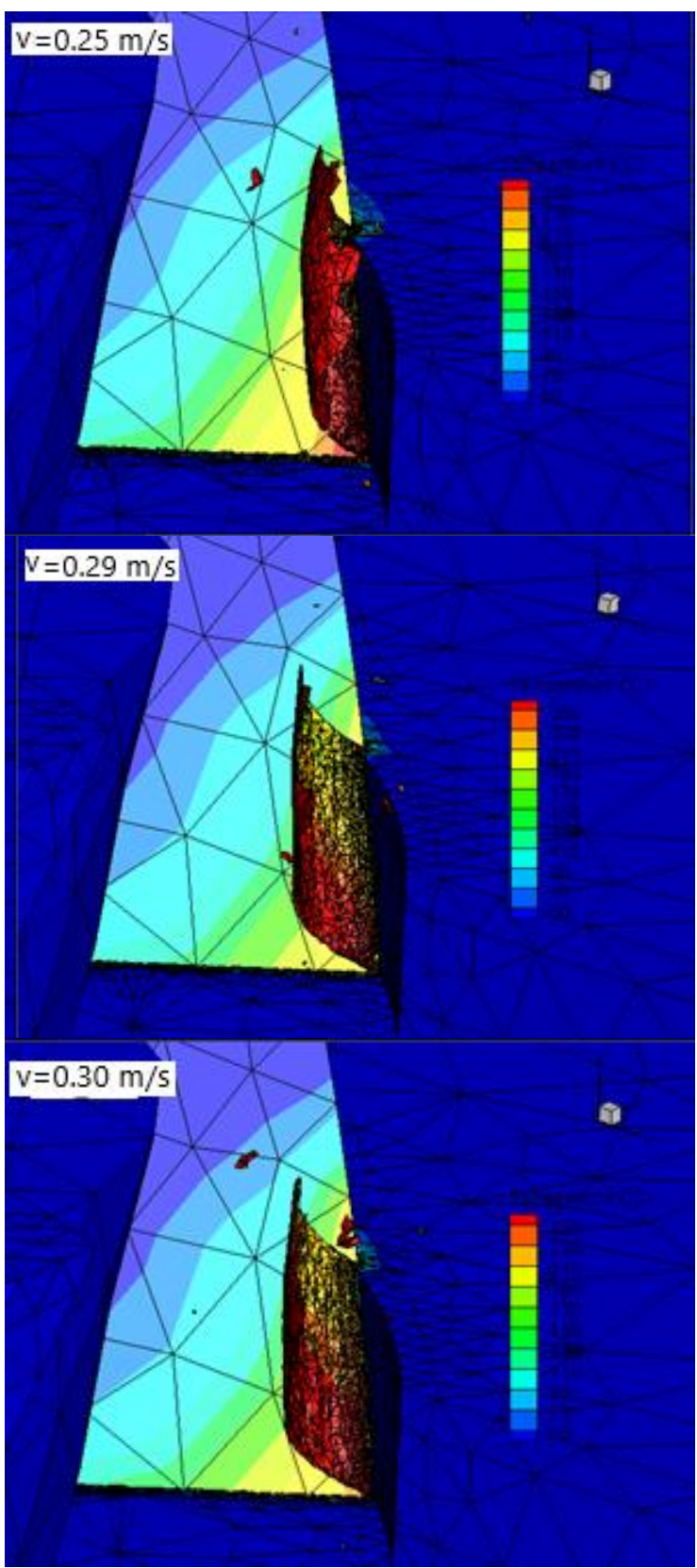

Fig. 1. Comparison simulation with different cutting speeds.

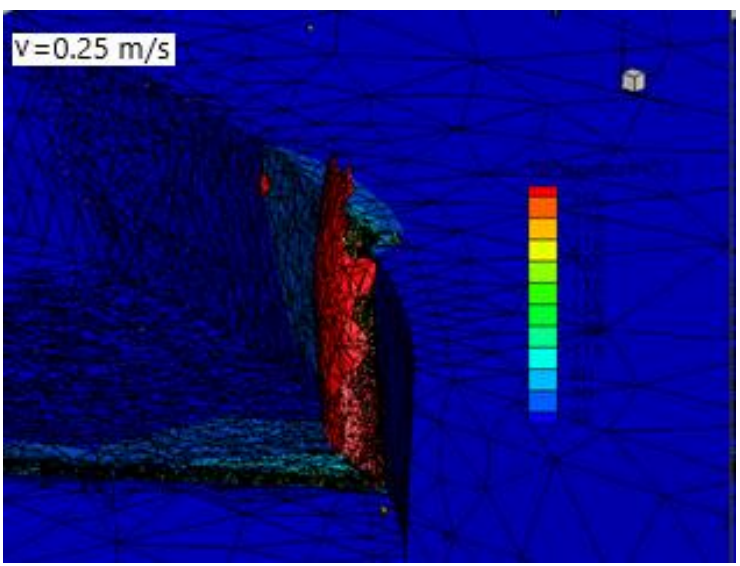




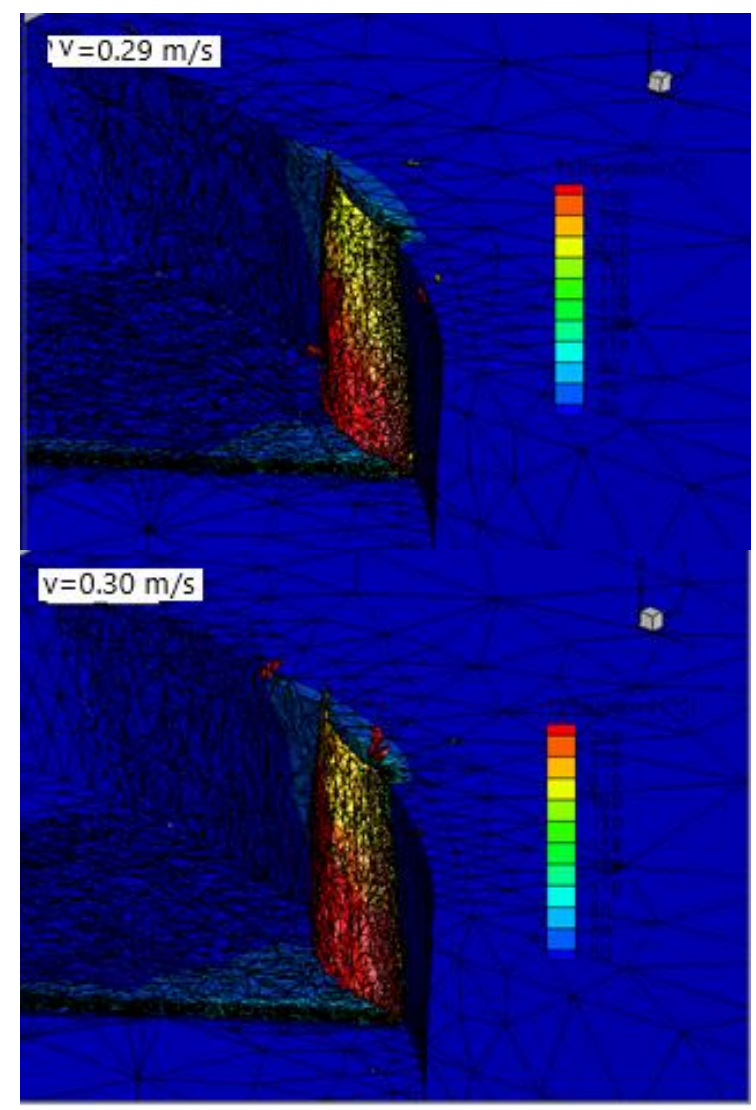

Fig. 2. Comparative simulation of temperature without tool display.

Figure 4 shows the comparative temperature diagrams in the cutting zone (the highest value) versus the machining time. From the diagram it can be noticed that at the beginning of machining the highest temperature is achieved with the highest cutting speed and that at a lower cutting speed, more time should be allowed to achieve the maximum temperature value.

Figure. 5 shows a temperature dependence diagram of an angular processing length. As with the previous diagrams for an angular processing length of $90{ }^{\circ} \mathrm{C}$, it can be seen that the temperature is rapidly decreasing at half the machining length.

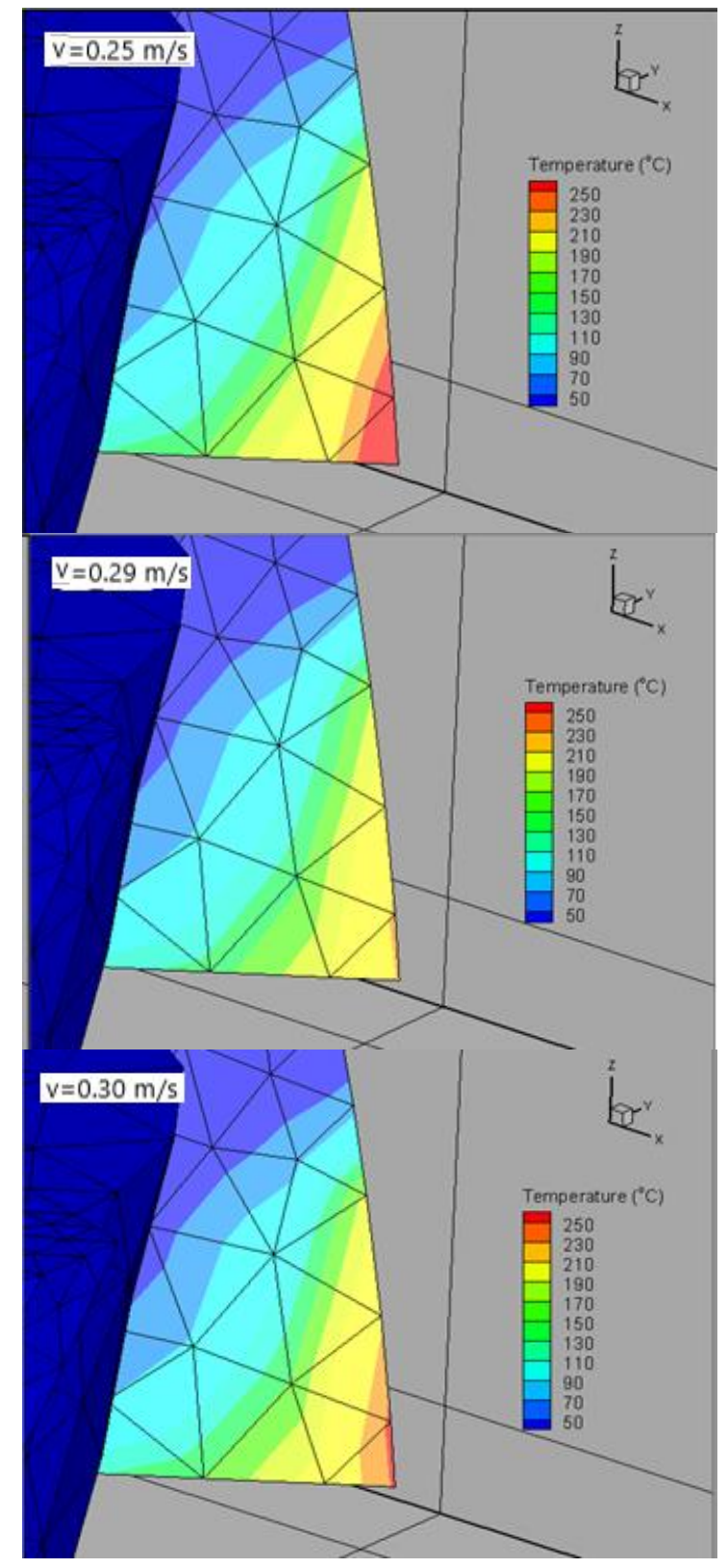

Fig. 3. Temperature on tool display on comparative simulations

\section{Peak Temperature vs Time}

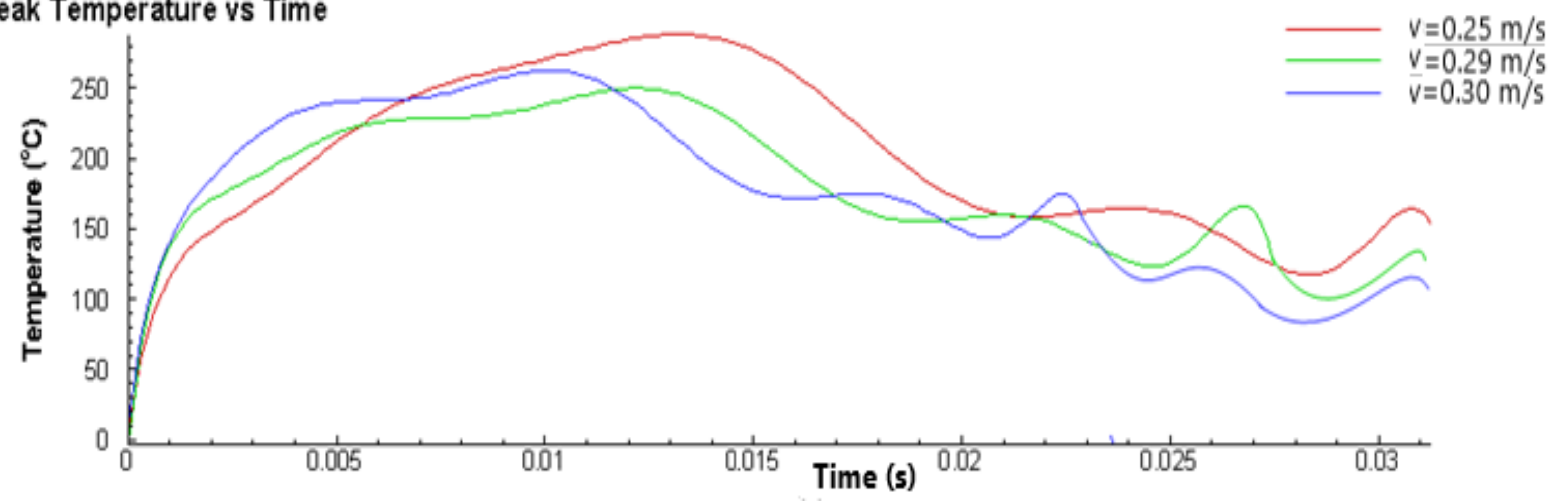

Fig. 4. Diagram of temperature-time simulation for different cutting speeds. 


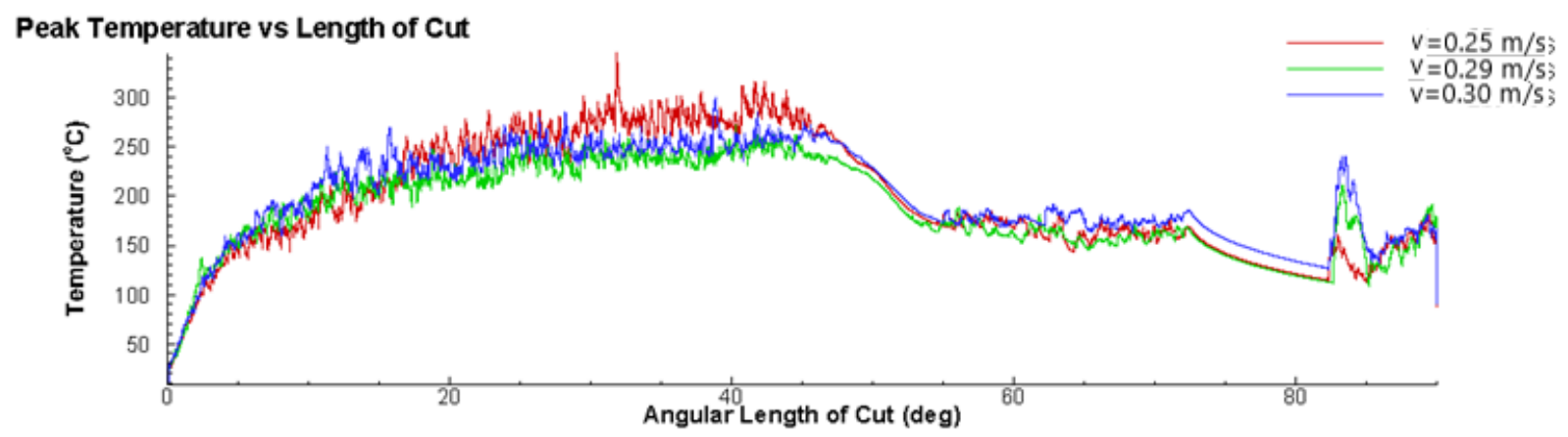

Fig. 5. Temperature dependence diagram versus angular processing length.

\section{Conclusion}

On the basis of the obtained results, it can be concluded that in the AdvantEdge software package, temperatures in the cutting zone for machining simulations can be analyzed with great reliability. For the appropriate treatment regimes, the influence of cutting speed on the temperature in the cutting zone can be conveniently analyzed. Precise geometry of the tool allows obtaining more reliable results in predicting temperature in the cutting zone, although this significantly influences the increase in the time required to process the simulation.

The results obtained by testing needs to be taken with the material irregularities that are formed during the production of the material, as well as the vibration on all machines.Equations should be centred and should be numbered with the number on the right-hand side.

\section{References}

1. P. Kovac, M. Gostimirovic, M. Sekulic, B. Savkovic A review to advanced modeling and simulation of machining process, Journal of Production Engineering, 12, 1 (2009), 17- 22.

2. P. Niesłony, W. Grzesik, W. Habrat, Experimental and simulation investigations of face milling process of Ti-6Al-4V titanium alloy, Advances in manufacturing science and technology, 39, 1 (2015)

3. C. Constantin, S. Croitoru, G. Constantin, E. Străjescu, FEM tools for cutting process modelling and simulation, UPB Scientific Bulletin, Mechanical engineering, (2012)

4. K. Kadirgama, M. Noor, M. Rahman, W. Harun, C. Haron, Finite Element Analysis and Statistical Method to Determine Temperature Distribution on Cutting Tool in End-Milling, European journal of scientific research, (2009)

5. J. Y. Wang, C. R. Liu, A new concept for decoupling the cutting forces due to tool flank wear and chip formation in hard turning, Mach SciTechnol 2, 1 (1998), 77-90.

6. I. Korkut,M. Boy, I. Karacan, U. Seker, Investigation of chip back temperature duringmachining depending on cutting parameters. Mater Des 28, (2007), 2329-2335.

7. S. Jaspers, J. Dautzenberg, D. Taminiau, Temperature measurement in orthogonal metal cutting. Int J Adv Manuf Technol 14, (1998), 7-12.

8. T. Ueda, M. Huda, K. Yamada, K. Nakayama, Temperature measurement of CBN tool in turning of high hardness steel. CIRP Ann 48, 1 (1999), 6366.

9. R. Tanaka, H. Motishita, Y. Lin, A. Hosokawa, T. Ueda, T. Furumoto, Cutting tool edge temperature in finish hard turning of case hardened steel. Key Eng Mater 407/408, (2009), 268-272.

10. A. Mitrovic, P. Kovač, N. Kulundžić, B. Savković, 3D finite element simulation of milling, Journal of Production Engineering, 19, 1 (2016), 31-34.

11. Third Wave Sistems AdvantEdge 7.1, User's manual, (2015) 